\title{
Periodontal Effects of Orthodontic Expansion Devices
}

\author{
Miral Agarwal, Ayush Jain, and Shradha Jain
}

\section{ABSTRACT}

The aim of this review article is to identify and present an overview on the effects of different palatal expansion device on periodontium. Orthodontic treatment is a popular option for adolescents and adult patients for achieving better alignment of teeth and better esthetics. Palatal expansion technique is useful in treatment of patients' malocclusion. With newer palatal expansion devices, patient's malocclusion can be treated in better way. It is important to understand that oral hygiene plays an important role in the maintenance of periodontal health during orthodontic treatment. In adult patients, regular monitoring regarding the periodontal health should be performed prior to and during orthodontic treatment.

Keywords: Maxillary expansion, orthodontic-periodontic relationship, periodontal inflammation, rapid maxillary expansion.

Published Online: September 20, 2021

ISSN: $2684-4443$

DOI: $10.24018 /$ ejdent.2021.2.5.93

\section{Miral Agarwal*}

MDS Periodontology, Agrawal's Dental Clinic, Dahod, Gujarat, India

(e-mail: miral_agarwal ${ }^{@}$ yahoo.co.in) Ayush Jain

MDS in orthodontia, Dr Jains Family Dental Care, Delhi, India.

Shradha Jain

MDS in orthodontia, Dr Jains Family Dental Care, Delhi, India.

*Corresponding Author

\section{INTRODUCTION}

Orthodontic treatment is becoming an increasingly popular option for correction of maligned teeth. Although it offers benefits of enhancing the esthetics of the patient, it does pose a risk to the periodontal tissues if proper care is not undertaken. There is a wide range of bacteria, fungi, and viruses that take shelter in the oral cavity. The bacteria in the oral cavity form a thin covering over the surfaces of teeth and gums known as plaque [1]. Plaque is the main factor responsible for the initiation, development and progress of gingival and periodontal disorders. But there are multiple other factors that can create conditions that are suitable for the progress of such disorders.

\section{ForCE DistribUtion WITH PALATAL EXPANSION TECHNIQUE}

During orthodontic treatment, forces are applied to the patient's teeth, which leads to the changes in the periodontal ligament and initiates the movement of teeth within the alveolar bone. Usually, this treatment can be undertaken without any significant issues if the periodontal health and hygiene is maintained properly. If the treatment is not undertaken properly due to either application of heavy forces or due to periodontal conditions such as juvenile aggressive periodontitis, it can lead to damage to the periodontium and alveolar bone.

Certain orthodontic interventions such as rapid maxillary expansion can be used for the correction of narrow maxilla. Correlation between orthodontic expansion devices and periodontal tissues have been found in previous studies [2][4]. When rapid maxillary expansion devices are used, the levels of the inflammatory markers increase in response to the orthodontic treatment. The type of expansion therapy can be an important factor contributing to this response in the periodontium. Orthodontic forces can lead to tooth movement by causing changes at a molecular level similar to that observed with inflammation but without sepsis or can be called as relatively sterile inflammation. It is important to make sure that there is no active periodontal inflammation before initiating orthodontic treatment. As orthodontic treatment in the presence of active periodontitis can lead to progression of periodontal disease and affect alveolar bone height.

\section{INFLUENCE OF THE DESIGN OF PALATAL EXPANSION TECHNIQUE ON THE FORCES ON PERIODONTIUM}

Rapid maxillary expansion applies transverse forces on the maxillary teeth [5]. In the palatal expansion technique, the maxillary expansion devices are connected to the premolar and molar teeth [6]. This leads to application of forces directly on these teeth. Currently, newer devices have been discovered which use mini-screws for the palatal expansion technique known as mini-screw supported rapid maxillary expansion (MARME or MARPE). With this device, as maxillary expansion is undertaken, the force is distributed over the mini-screws rather than the teeth [7]. This leads to lower amount of forces being exerted on the teeth. Consequently, the palatal width increases significantly with the use of MARME device. This leads to improvements in the airway of the patient in addition to the effects of increase in palatal width, specifically the nasopharyngeal airway [7].

Other types of design are four mini-screws palatal expansion technique [8]. In this technique, four mini-screws are used in place of two mini-screws. The force is 
distributed over the four mini-screws when the expansion device is opened [9]. Although this could increase the cost of the appliance with more mini-screws. A newer design for the palatal expansion technique is the unilateral expansion design known as U-MARPE [10]. This design applies palatal expansion force on one side of the maxilla. This different force distribution with MARME could be helpful in reducing the impact of orthodontic forces on periodontium.

\section{IMPORTANCE OF ORAL HYGIENE DURING ORTHODONTIC TREATMENT}

An important consideration of maintain good oral health before, during, and after orthodontic treatment with braces or aligners is oral hygiene. If the patient performs good oral hygiene, they tend to have lesser periodontal problems related to orthodontic treatment [11]. Consequently, it is important to demonstrate and reinforce to the patient, the different aspects of performing oral hygiene procedures regularly. In addition, the patient must be regularly seen by a periodontist or a general dentist prior to starting orthodontic treatment, during orthodontic treatment, and after orthodontic treatment to monitor the periodontal status. Appropriate periodontal prophylaxis should be performed at necessary intervals [12], [13].

\section{PERIODONTAL INDICES FOR EVALUATION OF PERIODONTAL STATUS}

To identify the effects of rapid palatal expansion on periodontal status of the patients, it is important to include patients without other dental disorders. Patients should be free of caries, any previous history of dental trauma, or fractures, or granulomas, etc. [14]. Patients should not have active periodontal disease characterized by deep periodontal pockets, periodontal inflammation, bleeding gums, excessive deposits of plaque and calculus. The patients should not present with loss of bone height prior to treatment. To identify the periodontal status of the teeth due to orthodontic treatment, different periodontal indices can be used such as periodontal index, gingival index [15]. With fixed orthodontic treatment, brushing is difficult and if the oral hygiene is not maintained, then the periodontal indices measurements may increase. This is why proper oral hygiene maintenance is important for the duration of orthodontic treatment [16]. Another effect of palatal expansion technique is on the alveolar bone [17]. The alveolar bone width can be affected with the application of palatal expansion technique. With the application of MARME palatal expansion technique, this effect could be reduced. This is due to the decreased amount on forces on the teeth and absorption of forces by the mini-screws [18]. This is also the reason why MARME palatal expansion technique does not lead to negative effects on Temporomandibular Joint (TMJ) [19].

\section{IMAGING FOR EVALUATION OF PERIODONTAL Status}

Computed Tomography (CT) had been introduced in medical field as a revolutionary imaging modality for 3dimensional analysis of the hard tissues [20]. It was soon applied in dental field for diagnosis and treatment outcomes. However, the radiation dose of CT scan is higher than the normal dental radiographic imaging techniques. But normal dental radiographic imaging technique such as orthopantomography and lateral cephalograph cannot be used to measure bone and root accurately and reliably as they show variation with head and neck position error [21]. To reduce the radiation dose and apply 3 dimensional imaging to dental field, cone beam computed tomography (CBCT) was introduced. CBCT can be used to identify the status of teeth and bone in 3 dimensions [22], [23]. It can be used as a tool for pretreatment evaluation for diagnosis and treatment planning as well as for posttreatment evaluation and evaluation of treatment outcomes [24], [25]. Thus, the periodontal status of the teeth can be identified by evaluating the bone dimensions after palatal expansion technique [26], [27].

\section{PERIODONTIUM IN AdULTS With ORTHODONTIC TREATMENT}

Periodontal health is often not ideal in adult patients when they present for orthodontic consultation [28]. Such patients are likely to have gingivitis, periodontitis, deep periodontal pockets, gingival recession, gingival swelling, horizontal or vertical alveolar bone loss, root resorption, attrition, missing teeth, restored teeth, etc. Often, such patients required interdisciplinary treatment. The factor responsible for periodontal diseases in adults is the same as that in adolescents - plaque [12]. The presence of microorganisms in plaque lead to the development of periodontal disease and its progression to the various stages. It is necessary to identify the status and perform appropriate treatment of the periodontium prior to starting orthodontic treatment [29]. The reduction of periodontal pockets with appropriate periodontal therapy should be performed prior to orthodontic treatment. Some medical conditions and medications further complicate orthodontic treatment and tooth movement. Patients with habits such as smoking should be cautioned about the negative effects of smoking on periodontal health [30]. If periodontal health is not well controlled in this patients, orthodontic treatment can lead to aggravation of the existing condition. But, if well controlled, then orthodontic treatment can be performed adequately.

\section{CONCLUSION}

Periodontal health is critical for the proper maintenance and longevity of teeth. In patients of different age group, periodontal needs may be different. Palatal expansion technique in orthodontics can help in treatment of patient's malocclusion. With the newer expansion devices, palatal expansion technique can be used in a better way. Interdisciplinary collaboration with periodontists and orthodontists can ensure that the periodontal health of patients undergoing orthodontic treatment is maintained. 
Specially in adult patients, it is important that the periodontal health be monitored regularly.

\section{REFERENCES}

[1] P.D. Marsh, "Are dental diseases examples of ecological catastrophes?," Microbiology, vol. 149, pp. 279-294, Feb. 2003.

[2] S. E. Bishara, and R. N. Staley, "Maxillary expansion: clinical implications," American journal of orthodontics and dentofacial orthopedics : official publication of the American Association of Orthodontists, its constituent societies, and the American Board of Orthodontics, vol. 91, pp. 3-14, Jan. 1987.

[3] W. G. Grieve, 3rd, G. K. Johnson, R. N. Moore, R. A. Reinhardt, and L. M. DuBois "Prostaglandin E (PGE) and interleukin-1 beta (IL-1 beta) levels in gingival crevicular fluid during human orthodontic tooth movement," American journal of orthodontics and dentofacial orthopedics: official publication of the American Association of Orthodontists, its constituent societies, and the American Board of Orthodontics, vol. 105,4, pp. 369-74, Apr. 1994.

[4] L. Ousehal, L. Lazrak, R. Es-Said, H. Hamdoune, F. Elquars, and A. Khadija, "Evaluation of dental plaque control in patients wearing fixed orthodontic appliances: a clinical study," International orthodontics, vol. 9, pp. 140-55, Mar. 2011.

[5] A J. Haas, "The treatment of maxillary deficiency by opening the midpalatal suture," The Angle orthodontist, vol. 35, pp. 200-17, July 1965.

[6] S. Abu Arqub, S. Mehta, M. G. Iverson, S. Yadav, M. Upadhyay, and M. Almuzian, "Does Mini Screw Assisted Rapid Palatal Expansion (MARPE) have an influence on airway and breathing in middle-aged children and adolescents? A systematic review," International orthodontics, vol. 19, pp. 37-50, Mar. 2021.

[7] S. Mehta, D. Wang, C. L. Kuo, J. Mu, M. L. Vich, V. Allareddy, et al. "Long-term effects of mini-screw-assisted rapid palatal expansion on airway," The Angle orthodontist, vol. 91, pp. 195-205, Mar. 2021.

[8] K. J. Lee, Y. C. Park, J. Y. Park, and W. S. Hwang. "Miniscrewassisted nonsurgical palatal expansion before orthognathic surgery for a patient with severe mandibular prognathism," American journal of orthodontics and dentofacial orthopedics: official publication of the American Association of Orthodontists, its constituent societies, and the American Board of Orthodontics, vol. 137, pp. 830-9, June 2010.

[9] H. Wehrbein, B. R. Merz, and P. Diedrich, "Palatal bone support for orthodontic implant anchorage--a clinical and radiological study," European journal of orthodontics, vol. 21, pp. 65-70, Feb. 1999.

[10] J. Dzingle, S. Mehta, P. J. Chen, and S. Yadav "Correction of Unilateral Posterior Crossbite with U-MARPE." Turkish journal of orthodontics, vol. 33, pp. 192-196, July 2020.

[11] A. Dannan, "An update on periodontic-orthodontic interrelationships," Journal of Indian Society of Periodontology, vol. 14, no. 1, pp. 66-71, Jan. 2010.

[12] R. J. Genco and W. S. Borgnakke, "Risk factors for periodontal disease," Periodontology 2000, vol. 62, no. 1, pp. 59-94, June 2013.

[13] Zachrisson B. U., "Clinical implications of recent orthodonticperiodontic research findings," Seminars in orthodontics, vol. 2, pp. 4-12, Mar. 1996.

[14] V. Krishnan, R. Ambili, Z. Davidovitch, and N. C. Murphy, "Gingiva and Orthodontic Treatment," Seminars in Orthodontics, vol. 13, no. 4, pp. 257-271, Dec. 2007.

[15] N. L. Sanders, "Evidence-based care in orthodontics and periodontics: a review of the literature," Journal of the American Dental Association, vol. 130, no. 4, pp. 521-527, Apr. 1999.

[16] S. Mummolo, E. Marchetti, M. R. Giuca, G. Gallusi, S. Tecco, R. Gatto, and G. Marzo, "In-office bacteria test for a microbial monitoring during the conventional and self-ligating orthodontic treatment," Head \& face medicine, vol. 9 pp. 1 Feb. 2013.

[17] J. E. Lupi, C. S. Handelman, and C. Sadowsky, "Prevalence and severity of apical root resorption and alveolar bone loss in orthodontically treated adults," American journal of orthodontics and dentofacial orthopedics: official publication of the American Association of Orthodontists, its constituent societies, and the American Board of Orthodontics, vol. 109, pp. 28-37, Jan. 1996.

[18] J. J. Park, Y. C. Park, K. J. Lee, J. Y. Cha, J. H. Tahk, and Y. J. Choi, "Skeletal and dentoalveolar changes after miniscrew-assisted rapid palatal expansion in young adults: A cone-beam computed tomography study," Korean journal of orthodontics, vol. 47, pp. 7786, Mar. 2017.

[19] S. Mehta, P. J. Chen, M. L. Vich, M. Upadhyay, A. Tadinada, and S. Yadav, "Bone-anchored versus tooth-anchored expansion appliances: Long-term effects on the condyle-fossa relationship," Journal of the
World federation of orthodontists, S2212-4438(21)00031-X, July 2021.

[20] C. C. Tai, I. S. Sutherland, and L. McFadden, "Prospective analysis of secondary alveolar bone grafting using computed tomography," Journal of oral and maxillofacial surgery: official journal of the American Association of Oral and Maxillofacial Surgeons, vol. 58, pp. 1241-9, Nov. 2000

[21] S. Mehta, R. Dresner, V. Gandhi, P. J. Chen, V. Allareddy, C. L. Kuo, et al., "Effect of positional errors on the accuracy of cervical vertebrae maturation assessment using CBCT and lateral cephalograms." Journal of the World federation of orthodontists, vol. 9, pp. 146-154, Dec. 2020.

[22] S. Akyalcin, S. P. Alexander, R. M. Silva, and J. D. English, "Evaluation of three-dimensional root surface changes and resorption following rapid maxillary expansion: a cone beam computed tomography investigation." Orthodontics \& craniofacial research, vol. 18, pp. 117-26., Apr. 2015

[23] V. C. Cook, A. M. Timock, J. J. Crowe, M. Wang, and D. A. Covell $\mathrm{Jr}$, "Accuracy of alveolar bone measurements from cone beam computed tomography acquired using varying settings," Orthodontics \& craniofacial research, vol. 18, pp. 127-36, Apr. 2015.

[24] C. C. Leung, L. Palomo, R. Griffith, and M. G. Hans, “Accuracy and reliability of cone-beam computed tomography for measuring alveolar bone height and detecting bony dehiscences and fenestrations," American journal of orthodontics and dentofacial orthopedics: official publication of the American Association of Orthodontists, its constituent societies, and the American Board of Orthodontics, vol. 137, pp. S109-19, Apr. 2010.

[25] A. M. Timock, V. Cook, T. McDonald, M. C. Leo, J. Crowe, B. L. Benninger, and D. A. Covell Jr, "Accuracy and reliability of buccal bone height and thickness measurements from cone-beam computed tomography imaging," American journal of orthodontics and dentofacial orthopedics: official publication of the American Association of Orthodontists, its constituent societies, and the American Board of Orthodontics, vol. 140,pp. 734-44, Nov. 2011.

[26] Z. Sun, T. Smith, S. Kortam, D. G. Kim, B. C. Tee, and H. Fields, "Effect of bone thickness on alveolar bone-height measurements from cone-beam computed tomography images." American journal of orthodontics and dentofacial orthopedics: official publication of the American Association of Orthodontists, its constituent societies, and the American Board of Orthodontics, vol. 139, pp. e117-27, Feb. 2011.

[27] L. Sun, L. Zhang, G. Shen, B. Wang, and B. Fang, "Accuracy of cone-beam computed tomography in detecting alveolar bone dehiscences and fenestrations." American journal of orthodontics and dentofacial orthopedics: official publication of the American Association of Orthodontists, its constituent societies, and the American Board of Orthodontics, vol. 147, pp. 313-23, Mar. 2015.

[28] U. Bragger and N. P. Lang, "The significance of bone in periodontal disease," Seminars in Orthodontics, vol. 2, no. 1, pp. 31-38, Mar. 1996.

[29] L. Ousehal, L. Lazrak, R. Es-Said, H. Hamdoune, F. Elquars, and A. Khadija, "Evaluation of dental plaque control in patients wearing fixed orthodontic appliances: a clinical study," International orthodontics, vol. 9, pp. 140-55, Mar. 2011.

[30] T. P. Garlet, U. Coelho, C. E. Repeke, J. S. Silva, F. Cunha, and G. P. Garlet, "Differential expression of osteoblast and osteoclast chemmoatractants in compression and tension sides during orthodontic movement," Cytokine, vol. 42, pp. 330-5, June 2008.

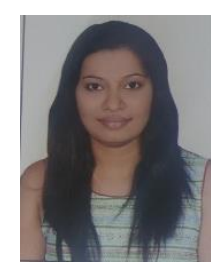

Dr. Miral Agarwal from Dahod, Gujarat, India,was born on 19/10/1987. She has done her B.D.S from Government Dental college and hospital, AHMEDABAD in 2010 and M.D.S in Periodontology in 2014 from Government Dental college and hospital, Ahmedabad, Gujarat, India.

She has done Rotational Internship in 2009-2010 from Government Dental college and hospital, Ahmedabad, Post Graduation in Periodontology in 2011 to 2014 from Government Dental college and hospital, Ahmedabad. She is practicing as a Periodontist and Implantologist from 2014 till date around 7 years at Agrawal's Dental Clinic, Dahod, Gujarat, India.

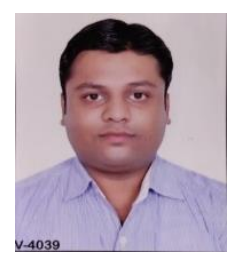

Dr. Ayush Jain from Delhi, born on 26/12/1988. have done B.D.S from Maharishi Markendeshwar College of Dental Science and Research in 2010 and M.D.S in Orthodontia from Subharti Dental College Meerut, Uttar Pradesh, India.

He has done Rotational internship in 2010- 2011 from Government Dental college and hospital, 
Rohtak, Haryana and Post Graduation in Orthodontia in 2016 from Subharti Dental College Meerut, Uttar Pradesh, India. He is practicing as an Orthodontist from 2016 till date at Dr. Jain's Dental care, Delhi, India.

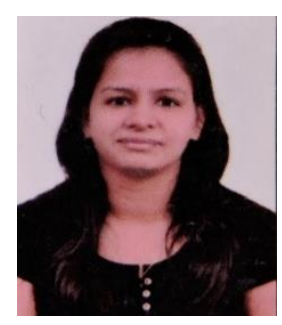

Dr. Shradha Jain from Delhi was born on 30/09/1986. She has done B.D.S from Maharishi Markendeshwar College of Dental Science and Research in 2010 and M.D.S Post Graduation in Periodontology in 2012 to 2015 from Government Dental college and hospital, Ahmedabad.

She has done Rotational internship in 20102011 from Government Dental college and hospital, Rohtak, Haryana and Post Graduation in Periodontology in 2012 to 2015 from Government Dental college and hospital, Ahmedabad, Gujarat, India. She is practicing as a Periodontist from 2016 till date at Dr. Jain's Dental care, Delhi, India. 